\section{Regards sur l'économie allemande}

Bulletin économique du CIRAC

116-117| 2015

Varia

\title{
Inquiétantes dissonances franco-allemandes dans la crise grecque
}

René Lasserre

\section{OpenEdition}

Édition électronique

URL : http://journals.openedition.org/rea/4808

DOI : 10.4000/rea.4808

ISSN : 1965-0787

Éditeur

CIRAC

\section{Édition imprimée}

Date de publication : 1 juillet 2015

Pagination : 1-2

ISSN : 1156-8992

\section{Référence électronique}

René Lasserre, «Inquiétantes dissonances franco-allemandes dans la crise grecque », Regards sur

l'économie allemande [En ligne], 116-117 | juillet 2015, mis en ligne le 01 juillet 2015, consulté le 22 septembre 2020. URL : http://journals.openedition.org/rea/4808 ; DOI : https://doi.org/10.4000/rea. 4808 


\section{Inquiétantes dissonances franco-allemandes dans la crise grecque}

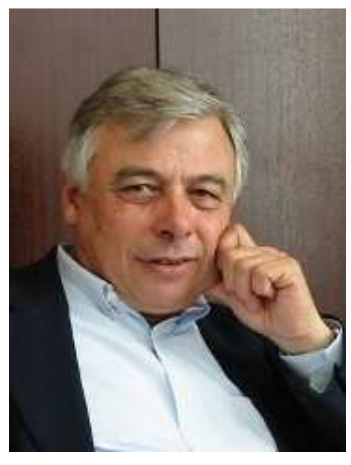

Le resserrement du couple franco-allemand engagé depuis l'automne dernier avec la gestion conjointe de la crise ukrainienne, la solidarité affichée face au terrorisme, la préparation concertée du sommet climatique et la conduite des négociations financières avec la Grèce au sein de l'Eurogroupe s'est trouvé fortement ébranlé par l'incroyable coup de poker engagé par Alexis Tsipras au soir du 27 juin.

En prenant le contre-pied d'une décision logique de suspension des négociations partagée par l'ensemble de l'Eurogroupe, le Président François Hollande n'a pas hésité à marquer sa distance à l'égard de ses partenaires, en premier lieu avec le gouvernement allemand, taxé implicitement d'intransigeance et de brutalité. Le président n'a été guère mieux inspiré dans son exigence de voir poursuivre coûte que coûte et dans l'urgence la recherche d'un compromis permettant d'échapper au dilemme désormais inévitable du maintien ou de la sortie de la Grèce de la zone Euro. Outre la désarmante mansuétude dont elle témoignait pour le cynisme du gouvernement grec, cette proposition de dernière minute manquait de réalisme, tant par l'étroitesse de ses possibilités techniques que par l'inexistence des soutiens politiques dont elle semblait susceptible de bénéficier de la part de l'Espagne ou de l'Italie. Le rejet pur et simple par l'Eurogroupe de la proposition du président français permit ainsi de mesurer son isolement désormais patent face au consensus européen sur la stabilité de l'Euro.

Par cet aval un peu vite donné au gouvernement grec, François Hollande n'a pas pleinement assumé ses responsabilités de chef d'Etat de la seconde puissance économique de l'UE. Plutôt que de rappeler ses protégés de Syriza au respect de leurs engagements, il leur a laissé entrevoir la perspective d'une nouvelle échappatoire, délivrant ainsi un nouveau message ambigu au peuple grec à la veille d'une consultation majeure.

A se demander si, au regard de ses maigres chances à faire bouger l'échiquier européen, cette déclaration présidentielle ne procédait pas plutôt d'une opération de politique intérieure visant à affirmer opportunément les contours de la posture euro-critique du futur candidat François Hollande dans l'opinion politique française. En cautionnant moralement la surenchère du gouvernement Tsipras, il cède à la tentation de s'ériger en héraut d'une Europe qui souffre. Plus qu'il ne peut le faire à travers le maigre bilan de sa politique économique et sociale domestique, il saisit l'occasion qui lui est ainsi donnée de se singulariser dans l'espace public européen et de se muer en porte-parole tribunicien des victimes d'une Europe technocratique privilégiant les lois du marché, l'austérité budgétaire et la stabilité monétaire.

Prof. René Lasserre, Directeur du CIRAC 
Restant par ailleurs partie prenante de la solution qui devra être en tout état de cause apportée à l'insolvabilité grecque quel que soit le résultat du référendum du 5 juillet, le président ne devrait pas manquer de continuer à cultiver sa différence sur ce terrain en vue de recoller les fissures à l'intérieur du parti socialiste et de trouver une audience attentive au sein de la gauche anti-européenne. Cela devrait efficacement servir une stratégie de rassemblement visant à assurer la prééminence du candidat Hollande dans les primaires de la Gauche en 2016 puis, au premier tour de l'élection présidentielle de 2017, à reconquérir quelque audience aux franges de l'électorat du Front national.

Mais au-delà des postures partisanes et des conjectures électoralistes qui l'inspirent, l'ambiguïté du positionnement présidentiel face à l'insolvabilité grecque témoigne d'une ambivalence et d'une crise de crédibilité beaucoup plus profondes de la politique économique française. En dépit des perspectives rassurantes que distille le gouvernement sur l'amélioration transitoire de la conjoncture, les fondamentaux de l'économie française continuent de se dégrader : la stagnation de l'activité perdure, le chômage ne cesse d'augmenter, entretenus l'un et l'autre par l'accumulation des déficits et l'irrésistible envolée de la dette publique. Il reste à espérer que, dans le scénario d'une crise financière majeure qui n'est pas à exclure, ces fragilités n'empêcheront pas la France d'assumer pleinement, auprès de ses partenaires, les responsabilités historiques qui sont les siennes dans la sauvegarde d'une Union monétaire solide, garante de la stabilité de l'Europe.

René Lasserre, le 3 juillet 2015 